Archives

4| 1989

Varia

\title{
Ouvrages publiés par les membres du CRH en 1988/1989
}

\section{(2) OpenEdition}

Journals

Édition électronique

URL : http://journals.openedition.org/ccrh/2914

DOI : $10.4000 /$ ccrh.2914

ISSN : $1760-7906$

Éditeur

Centre de recherches historiques - EHESS

\section{Édition imprimée}

Date de publication : 15 octobre 1989

ISSN : 0990-9141

Référence électronique

"Ouvrages publiés par les membres du CRH en 1988/1989 ", Les Cahiers du Centre de Recherches Historiques [En ligne], 4 | 1989, mis en ligne le 13 avril 2009, consulté le 10 décembre 2020. URL : http://journals.openedition.org/ccrh/2914 ; DOI : https://doi.org/10.4000/ccrh.2914

Ce document a été généré automatiquement le 10 décembre 2020.

Article L.111-1 du Code de la propriété intellectuelle. 


\section{Ouvrages publiés par les membres du CRH en 1988/1989}

1 Cette liste ne comporte que les titres des ouvrages publiés, à l'exclusion des articles parus dans des revues scientifiques ou dans des Actes de colloque.

Hélène ANTONIADIS, Byzance et le mode de production asiatique (traduction grecque avec une nouvelle introduction), Athènes, 1988, $57 \mathrm{p}$.

Louis BERGERON, «L'espace du capital », in Histoire de la France, tome 1, Paris, Le Seuil, 1989.

«L'économie française et la Révolution », in La Révolution, la France et l'Allemagne, Paris, Editions de la MSH, 1989.

"Les conséquences économiques de la Révolution de 1789 », in Ecorama 88-89, Paris, Nathan, 1988.

Patrice BOURDELAIS, « Le Paysage humain », in Histoire de la France, tome 1, Paris, Le Seuil, 1989.

«Les structures », in Histoire de la population française, sous la direction de J. DUPAQUIER, volume 3, PUF, 1988.

Roger CHARTIER, Cultural history between practices and representations (trad. par Lydia G. Cochrane), Cambridge, Polity Press, 1988, 209 p.

Letture e lettori nella Francia di Antico Regime (trad. par Giovanna Astorri et Raffaella Comaschi), Turin, G. Einaudi ed., 1988, 238 p.

A Historia cultural entra praticas e representacoes (trad. par Maria Manuela Galhardo), Lisbonne, Difel, 1988, 244 p.

Luigi Einaudi, between politics and history; the inaugural lecture of the Luigi Einaudi chair at Cornell University, trad. par Cynthia J. Koepp, Western societies program, Cornell University, 1988, $48 \mathrm{p}$.

«Frenchness in the history of the book : from the history of publishing to the history of reading", James Russel Wiggins lecture in the history of the book in american culture, Worcester, American antiquarian society, 1988, $35 \mathrm{p}$.

La rapresentazione del sociale. Saggi di storia culturale (trad. par Andrea Carlino et Pippo Vitellio), Turin, Bollati Boringhieri, 1989, $231 \mathrm{p}$.

Paul COURBIN, What is archeology ?, Chicago University Press, 1988, XXV + 197 p. 
Arlette FARGE et Jacques REVEL, Logiques de la foule. L'Affaire des enlèvements d'enfants, Paris 1750, Paris, Hachette, coll. Textes du Xx ${ }^{\mathrm{e}}$ siècle, 1988.

Le goût de l'archive, Paris, le Seuil, coll. La librairie du Xx siècle, 1989, 156 p.

Marc FERRO, Cinema and history, Wayne University Press, 1988. (version complétée et mise à jour).

Der Grosse Krieg 1914-1918, Suhrkamp, 1988. (traduction, version complétée et mise à jour)

L'histoire sous surveillance, édition japonaise, 1988.

François FURET, La Révolution (1770-1880), Paris, Hachette, 1988.

Dictionnaire critique de la Révolution française (en collaboration avec Mona Ozouf), Paris, Flammarion, 1988.

Les orateurs de la Révolution, tome 1, Les Constituants (en collaboration avec Ran Halévi), Paris, Gallimard, Collection La Pléiade, 1989.

Ran HALEVI, Les orateurs de la Révolution... Cf. supra

François HARTOG, Le XIX ${ }^{e}$ siècle et l'histoire : le cas Fustel de Coulanges, Paris, PUF, 1988.

Dominique JULIA et Jacques REVEL, Les universités européennes $d u X^{X} I^{\mathrm{e}}$ au XVIII ${ }^{\mathrm{e}}$ siècle. Histoire sociale des populations étudiantes, tome 2 : France, Paris, Editions de l'EHESS, 1989.

Christiane KLAPISCH-ZUBER, La famiglia e le donne nel Rinascimento a Firenze, Bari, Laterza, 1988.

I Toscani e le loro famiglie. Uno studio sul catasto fiorentino del 1424, en collaboration avec David HERLIHY, Bologne, Il Mulino, 1988. (Traduction italienne de l'ouvrage paru en 1978 aux Presses de la FNSP).

Bernard LEPETIT, Les villes dans la France moderne (1740-1840), Paris, Albin Michel, 1988, $490 \mathrm{p}$.

Marie-Laurence NETTER, La Révolution française n'est pas terminée, Paris, PUF, 1989.

Jean-Claude PERROT, Lavoisier, de la richesse territoriale du royaume de France, texte et documents présentés par J-C. PERROT, Paris, Editions du Comité des travaux historiques et scientifiques, $269 \mathrm{p}$.

Jacques REVEL, tome 1, «L'espace français », in Histoire de la France, Le Seuil, 1989.

Jacques REVEL et Arlette FARGE, Logiques de la foule. L'Affaire des enlèvements d'enfants, Paris, 1750, Paris, Hachette, 1988.

Jacques REVEL et Dominique JULIA, Les universités européennes du XVI au XVIII siècle. Histoire sociale des populations étudiantes, tome 2 : France, Paris, Editions de l'EHESS, 1989.

Madeleine REBERIOUX, Ils ont pensé les droits de l'homme, EDI, 1989.

Daniel ROCHE, La culture des apparences. Une histoire du vêtement (XVII ${ }^{\mathrm{e}}-\mathrm{XVIII}{ }^{\mathrm{e}}$ siècle), Paris, Fayard, 1989.

Bernard ROSIER, L'histoire ambiguë, croissance et développement en question, Paris, PUF, 1988. En collaboration avec Pierre DOLKES.

Ouvrages collectifs :

Louis BERGERON (sous la direction de), Parigi, Bari, Laterza, 1989. Parait simultanément en novembre avec l'édition française: Paris, genèse d'un paysage, Picard. (Autres collaborateurs de l'ouvrage: Anne Lombard-Jourdan, Simone Roux, Jean Nagle, Pierre Pinon, Marcel Roncayolo).

Patrice BOURDELAIS (en collaboration avec J.P. BARDET, J.P. GUILLAUME, F. LEBRUN et C.QUETEL), Peurs et terreurs face à la contagion, Paris, Fayard, 1988, 442 p.

Roger CHARTIER (sous la direction de), A history of private life, tome 3: Passions of the Renaissance, trad. par A. Goldhammer, Cambridge, Mass., et London, The Belkhnap Press of Harvard University Press, 1989. Ouvrage également publié en espagnol (trad. par M. Concepcion Martin Morero), Madrid, Taurus, 1989. 